University of Nebraska - Lincoln

DigitalCommons@University of Nebraska - Lincoln

Sociology Department, Faculty Publications

Sociology, Department of

$9-2006$

\title{
Prevalence and Comorbidity of Mental Disorders among American Indian Children in the Northern Midwest
}

Les B. Whitbeck

University of Nebraska-Lincoln, Iwhitbeck2@unl.edu

Kurt D. Johnson

University of Nebraska-Lincoln, kdj11@psu.edu

Dan R. Hoyt

University of Nebraska-Lincoln, dhoyt2@unl.edu

Melissa L. Walls

University of Minnesota-Duluth, mlwalls@umn.edu

Follow this and additional works at: https://digitalcommons.unl.edu/sociologyfacpub

Whitbeck, Les B.; Johnson, Kurt D.; Hoyt, Dan R.; and Walls, Melissa L., "Prevalence and Comorbidity of Mental Disorders among American Indian Children in the Northern Midwest" (2006). Sociology Department, Faculty Publications. 209.

https://digitalcommons.unl.edu/sociologyfacpub/209

This Article is brought to you for free and open access by the Sociology, Department of at DigitalCommons@University of Nebraska - Lincoln. It has been accepted for inclusion in Sociology Department, Faculty Publications by an authorized administrator of DigitalCommons@University of Nebraska - Lincoln. 


\title{
Prevalence and Comorbidity of Mental Disorders among American Indian Children in the Northern Midwest
}

\author{
Les B. Whitbeck, Kurt D. Johnson, Dan R. Hoyt, and Melissa L. Walls \\ Department of Sociology, University of Nebraska-Lincoln, Lincoln, Nebraska \\ Corresponding author - Dr. Les B. Whitebeck, Department of Sociology, University of Nebraska-Lincoln, \\ 739 Oldfather Hall, Lincoln, NE 68588-0324; email 1whitbeck2@unl.edu
}

\begin{abstract}
Purpose - To investigate the prevalence of mental disorder and comorbidity among American Indian children aged 10-12 years from four U.S. reservations and five Canadian reserves in the Northern Midwest.

Method - Specially trained Native interviewers administered the Diagnostic Interview for Children-Revised for 11 diagnostic categories to 736 tribally enrolled children (mean age 11 years) and their female caretakers.

Results - Prevalence rates are reported by child self-report, female caretaker reports, and combined caretakerchild reports. Twenty-three percent (combined caretaker-child reports) of the children met criteria for one of the 11 disorders and 9\% met criteria for two or more of the disorders. Externalizing disorders were more prevalent than internalizing disorders or substance abuse disorders. The strongest predictor of child mental disorder was a depressed female caretaker.

Conclusions - Nearly one-fourth of Native children met criteria for at least one mental disorder. The presence of early mental disorder is an important risk factor for substance use and mental health problems in later life. We need systematic research to identify risk and protective factors for early mental health problems and to identify barriers to services utilization so that we can develop empirically informed, culturally specific prevention programs that address these needs.
\end{abstract}

Keywords: American Indian children, Mental disorder, Substance abuse disorder

There are very few studies that report prevalence rates of mental disorder among American Indian children, and the best of these is now becoming dated. The first wave data from the Great Smoky Mountains Study (GSMS) are now more than a decade old [1]. The most recent epidemiological study of American Indians, the American Indian-Services Utilization, Psychiatric Epidemiology, Risk and Protective Factors Project (AI-SUPERPFP) includes subjects from age 15 years through adulthood, but does not provide information on younger children [2-4].

There are many reasons why there are no population studies of American Indian children. The most critical are cultural diversity, geographical dispersion, and relatively small populations of American Indian nations. There are major cultural differences between the 562 federally recognized tribes of the United States [5]. These small, culturally distinct populations create sampling problems that make generalizing American Indians as a group nearly impossible. The small percentages in national studies nearly always relegate American Indians to the "other" ethnic categories and usually include only urban Native people in the sampling frame. Adding to the challenges of diagnostic studies is the distrust of research in American Indian communities after years of exploitation by academic researchers whose careers have benefited, but left nothing behind in the communities studied [6-8]. 
Beals and colleagues [9], in their discussion of these and other challenges in doing research on mental disorders among American Indians, point out that smaller separate studies that focus on particular cultures and that replicate measures used in national studies could contribute to cumulative knowledge regarding the prevalence of mental disorders among American Indians. This research reports on the prevalence and correlates of 11 mental disorders among children aged 10-12 years who live on or near four rural American Indian reservations and five rural and remote Canadian First Nations reserves and share a single American Indian culture with minor variations in dialect in the Northern Midwest and Ontario, Canada. We use multivariate analyses to investigate the effects of social and family contexts on early mental disorder, including family structure, economic deprivation, and mental health of caretaking adults.

\section{Mental disorder among American Indian cultures}

The most cited study of mental disorder among American Indian children is the Great Smoky Mountains Study [1]. The sample contained 323 Cherokee children aged 9, 11, and 13 years who were compared with 933 similarly aged European American children. The American Indian children had a slightly lower overall prevalence of psychiatric disorders than the European American children; however, although rates of substance abuse were low as would be expected among this age group, the American Indian children were significantly more likely to meet criteria for substance abuse (1.2\%) than their European American counterparts (.1\%). This was the only statistically significant difference in prevalence of psychiatric disorders between the two groups.

\section{Methods}

\section{Procedures}

These data were collected as part of a three-year lagged sequential study currently underway on four American Indian reservations in the Northern Midwest and five Canadian First Nation reserves. Four of the Canadian Reserves are classified as "remote" in that they are considerable distances from even small towns and are accessed by nonpaved roads, by boat, over ice in winter, or by airplane. The data are from wave one of a study collected on two U.S. reservations and one Canadian Reserve from February through October $2002(n=401)$ and wave one of the second related study of two U.S. reservations and four "remote" Canadian reserves collected February through October $2003(n=345)$. The reserves and reservations share a common cultural tradition and language with minor regional variations in dialects. The sample is representative of one of the most populous indigenous cultures in the United States and Canada. The long-range purpose of the longitudinal study is to identify culturally specific resilience and risk factors that affect children's well-being and to then use the information to guide the development of culturally based interventions.

The project was designed in partnership with the participating reservations and reserves. Before the application funding, the research team was invited to work on these reservations, and tribal resolutions were obtained. As part of our agreement to work together, the researchers promised that participating reservations would be kept confidential in published reports. On each participating reservation, an advisory board was appointed by the tribal council. The advisory boards were responsible for advising on handling difficult personnel problems, advising on questionnaire development, reading reports for respectful writing, and assuring that published reports protected the identity of the respondents and the culture. Upon advisory board approval of the questionnaires, the study procedures and questionnaires were submitted for review by the university Institutional Review Board for approval.

All participating staff on the reservations were approved by the advisory board and were either tribal members or, in a few cases, nonmembers who are spouses of tribal members. To ensure quality of data collection, all the interviewers underwent special training for conducting computer-assisted personal interviewing for the diagnostic measures. The training included practice interviews and feedback sessions regarding interview quality. In addition, all of the interviewers completed required human subject protection training that emphasized the importance of confidentiality and taught procedures to maintain the confidentiality of data.

Each tribe provided a list of families of enrolled children aged 10-12 years who lived on or proximate to (within 50 miles) the reservation or reserve. We attempted to contact all families with a target child with in the specified age range. Families were recruited with a personal visit by an American Indian interviewer, at which time the project was explained to them. They were then presented with a gift of wild rice and invited to participate. If they agreed to be interviewed, each family member received $\$ 40$ for their time when the interviews were completed. The recruitment procedure resulted in an overall response rate of $79.4 \%$.

\section{Sample characteristics}

Prevalence statistics are reported using combined caretaker- and child-reported disorder criteria; because of this, our prevalence rates are based on the total sample of children who completed the diagnostic interviews $(\mathrm{n}=736)$. Our multivariate analyses include several independent variables that are based on female adult caretaker reports. Our decision to focus on female caretakers was based on two factors: 1) the adult males in our sample represent a heterogeneous group of persons in relation to the target adolescent (i.e., biological father, 
grandfather, uncle, boyfriend); and 2) we have reports from only 226 male adult caretakers for our adult diagnostic interviews. For these reasons, our logistic regression models are based on a valid sample size of $679 \mathrm{fe}-$ male adult caretakers and offspring. Listwise deletion of cases missing values on any of the included variables resulted in a final sample size of 656 for multivariate analyses. Only 23 cases, or $3.4 \%$ of our sample measures, contained missing values. An analysis of variance between cases with "full" and missing data on each variable revealed no significant between-group differences $(p<.05)$. The one exception to this was the variable single-parent $(p=.02)$. Cases from single-parent households were more apt to have missing values than those from two-parent households.

Because of recruitment errors and birthdays during the data collection period, the age of the adolescents ranged from 9 to 14 years. There are very few outliers aged 9 or 14 years. The majority of the children were between 10 and 13 years, with an average age of 11 years. The adolescents in this sample were almost evenly split by gender.

About one-third $(36 \%)$ of the families contained two biological parents and 28\% were single-parent households. The remaining families were of various configurations: mother-stepfather, mother living with other relatives (e.g., grandmothers, aunts, uncles), single biological fathers, child living with grandparents, or other multigenerational household configurations.

The distribution of income in this sample varies according to family structure. Single-parent households were twice as likely as two-parent households (includes stepfathers and live-ins) to have incomes of $\$ 15,000$ or less ( $46 \%$ vs. $23.5 \%)$. More than one-fourth $(27.9 \%)$ of singleparent households were getting by on $\$ 10,000$ or less per year. Median income for single parent families was under $\$ 20,000$ compared with about $\$ 25,000$ for two-parent families. Financial assistance was also common. About onehalf of single-parent $(53.5 \%)$ and one-third of two-parent households (34.7\%) received food stamps. Approximately one-half $(44 \%)$ of single-parent households and $28.9 \%$ of two-parent households received family assistance (TANF) or the Canadian equivalent in the past year.

\section{Measurement}

Descriptive statistics for all of the measures used in our analyses appear in Table 1. Because of the economic differences between single-parent and two-parent households, we included a dummy variable for living in a single-parent family in the regression analyses, with 1 indicating living in a family with only one parent and 0 indicating other types of family structure. Family financial strain was measured by adult responses to six questions regarding their family's financial situation [10]. Respondents stated whether their family had enough money to afford basic necessities such as shelter, clothing, and food, and the extent to which they were
Table 1. Descriptive statistics

\begin{tabular}{llll}
\hline & Mean/\% & SD & Range \\
\hline Child age & 11.08 & .82 & $9-13$ \\
Child gender & $50.0 \%$ & - & $0-1$ \\
Single-parent family & .28 & .45 & $0-1$ \\
Financial strain & 1.28 & .60 & $0-3$ \\
Remote location & .10 & .29 & $0-1$ \\
Female caretaker disorders (lifetime prevalence) & & \\
$\quad$ & $5.5 \%$ & - & $0-1$ \\
$\quad$ Generalized anxiety disorder & $63.6 \%$ & - & $0-1$ \\
$\quad$ Alcohol abuse & $19.5 \%$ & - & $0-1$ \\
$\quad$ Drug abuse & $19.2 \%$ & - & $0-1$ \\
$\quad$ Major depressive episode & & & \\
\hline
\end{tabular}

having difficulty paying their bills. Cronbach alpha for this measure was .81 .

We were concerned that living on a remote Canadian reserve may result in a very different social context from that of less remote U.S. reservations, particularly in regards to access to mental health services. Living in a remote residential location was measured by whether the children lived on one of the four "remote" Canadian reserves, with 1 indicating remote and 0 others. About $10 \%$ of our sample lived on these remote reservations.

We were able to include four diagnoses for female adult caretakers. The number of adult diagnoses was limited because of time constraints, but also because of cultural sensitivity expressed by advisory boards regarding the nature of questions for some of the diagnoses such as antisocial personality disorder and posttraumatic stress disorder. Diagnoses for the adult caretakers were from the University of Michigan Composite International Diagnostic Interview (UM-CIDI). The UM-CIDI is based on Diagnostic and Statistical Manual-III-R (DSM-III-R) criteria and represents the University of Michigan revision of the CIDI used in the National Comorbidity Survey (NCS) [11, 12]. The CIDI [13], from which the UM-CIDI is derived, is a well-established diagnostic instrument that has shown excellent inter-rater reliability, test-retest reliability, and validity for the diagnoses that were used in this study. The UM-CIDI has been used extensively with trained interviewers who are not clinicians. The version used in this study included cultural modifications similar to those in the AI-SUPERPFP $[3,4]$.

The most prevalent lifetime adult diagnosis among female caretakers was alcohol abuse $(63.6 \%)$. About $20 \%$ of the female caretakers met criteria for drug abuse and for major depressive episode. Approximately $6 \%$ met criteria for generalized anxiety disorder. Diagnoses were coded " 1 " when female caretakers met diagnostic criteria and " 0 " when they did not meet criteria.

Child diagnostic information from parents and child reports were obtained for 11 diagnoses. The substance abuse disorders (alcohol, alcohol dependence, marijuana 
abuse, marijuana dependence, nicotine dependence), major depressive episode, dysthymic disorder, general anxiety disorder, oppositional defiant disorder, conduct disorder, and inattention/hyperactivity disorder modules were used from the Diagnostic Interview Schedule for Children-Revised (DISC-R). The DISC-R is a highly regarded, structured interview intended for use with trained interviewers. Test-retest reliability for self-reports of children under 11 years of age varies by diagnostic category, with younger children being particularly unreliable reporters of onset and duration of symptoms. Parents tend to report more symptoms and to report them more reliably than children. The reliability of parent reports was excellent for inattention/hyperactivity, and fair for overanxious disorder, oppositional defiant disorder, and conduct disorder [14]. The DISC-R has been used extensively for children aged 11 years and older $[15,16]$.

In general, reliability research on various versions of the DISC indicate that parent reports are the most reliable and that combined parent-child reports are more reliable than child reports alone $[17,18]$. Bird and colleagues suggest that parents and children may each provide unique information regarding symptoms and that both sources of information are important for meaningful diagnosis [19]. Similarly, Jensen and colleagues argue that although discrepant caretaker and child reports provide meaningful information in some cases (e.g., attention deficit hyperactivity disorder), child reports should be treated cautiously [20]. Given the propensity of research that indicates combined reports provide the most inclusive information, we rely on combined caretaker and child reports for our multivariate analyses. If diagnostic criteria are met by either parent or child, or if the combined reports of symptoms meet criteria, they represent caseness in our analyses. To reflect the considerable variation between caretaker and child reports reflected in the literature, we report caretaker, child, and combined caretakerchild reports prevalence rates.

\section{Results}

\section{Prevalence}

Based on combined caretaker-child reports, $22.8 \%$ of the children met 12-month criteria for at least one mental disorder and $9 \%$ met 12 -month criteria for two or more disorders (Table 2). Children or caretaker reports alone resulted in lower rates of meeting criteria for single or cooccurring disorders.

Combined caretaker-child reports indicated that 1.4\% met 12-month criteria for alcohol abuse and 1.4\% met criteria for marijuana dependence (Table 2). These percentages were accounted for mostly by child self-reports. According to combined caretaker-child reports $1.2 \%$ of the children met criteria for 12-month nicotine dependence. Again, for child self-reported lifetime nicotine dependence, the prevalence is based mostly on child reports.
Table 2. Prevalence of DSM-III-R disorders among American Indian children (by \%)

\begin{tabular}{lrrr}
\hline 12-month criteria & $\begin{array}{r}\text { Children } \\
\text { report }\end{array}$ & $\begin{array}{r}\text { Caretaker } \\
\text { report }\end{array}$ & $\begin{array}{r}\text { Combined caretaker- } \\
\text { children report }\end{array}$ \\
\hline Alcohol abuse & 1.2 & .3 & 1.4 \\
Alcohol dependence & 0.0 & 0.0 & 0.0 \\
Marijuana abuse & 0.0 & .3 & .3 \\
Marijuana dependence & 1.2 & .3 & 1.4 \\
Nicotine dependence & .9 & .4 & 1.2 \\
Major depression & 2.3 & 1.4 & 3.6 \\
Dysthymic disorder & .7 & .1 & .8 \\
General anxiety & 1.6 & 2.6 & 4.1 \\
Conduct disorder & 5.2 & 4.2 & 8.6 \\
Inattention/hyperactive & 1.4 & 6.6 & 7.6 \\
Oppositional/Defiant & 2.6 & 5.5 & 7.9 \\
At least one disorder & 11.5 & 14.7 & 22.8 \\
Two or more disorders & 3.8 & 5.4 & 9.0 \\
\hline
\end{tabular}

$n=736$

The combined caretaker-child rate for 12-month major depressive episode was $3.6 \%$; child report was $2.3 \%$. The prevalence of generalized anxiety disorder was similar to that for major depressive episode; the combined caretaker-child prevalence rate was $4.1 \%$; child reports were lower at $1.6 \%$.

The highest prevalence rates were for behavioral disorders. According to combined caretaker-child reports, $7.9 \%$ met 12 -month criteria for opposition-defiant disorder. Child reports were lower at $2.6 \%$. The combined caretaker-child report of 12-month prevalence of conduct disorder was $8.6 \%$. Child reports were somewhat lower at $5.2 \%$ for conduct disorder. The combined caretaker-child rate for 12-month inattention-hyperactivity disorder was $7.6 \%$, with child reports much lower at $1.4 \%$.

In general, caretaker reports were lower than child reports of the substance abuse disorders and conduct disorder, but higher than child reports for inattention-hyperactive and oppositional-defiant disorders. This is congruent with other findings indicating that children are poor informants of oppositional-defiant disorder and inattention-hyperactivity disorder [19-21]. Based on combined caretaker-child reports, boys were significantly more likely to meet criteria for externalizing disorders than were girls. There was no significant difference between boys and girls for internalizing disorders.

\section{Comorbidity}

Table 3 reports combined caretaker-child reports of comorbidity rates for 12-month disorders. Prevalence rates are reported along the diagonal; co-occurrences of diagnoses are shown off the diagonal. The major co-occurring disorders are with conduct disorder. For example, seven of the 10 children who met criteria for alcohol abuse also met criteria for conduct disorder, as did seven of the 10 
Table 3. Comorbidity among American Indian children (combined caretaker-children reports, $\mathrm{n}=736$ )

\begin{tabular}{|c|c|c|c|c|c|c|c|c|c|c|c|}
\hline & 1 & 2 & 3 & 4 & 5 & 6 & 7 & 8 & 9 & 10 & 11 \\
\hline $\begin{array}{l}\text { 112-month } \\
\text { alcohol abuse }\end{array}$ & $10(1.4 \%)$ & & & & & & & & & & \\
\hline $\begin{array}{l}\text { 212-month } \\
\quad \text { alcohol dependence }\end{array}$ & $0(0.0 \%)$ & $0(0.0 \%)$ & & & & & & & & & \\
\hline $\begin{array}{l}\text { 312-month } \\
\text { marijuana abuse }\end{array}$ & $1(.1 \%)$ & $0(0.0 \%)$ & $2(.3 \%)$ & & & & & & & & \\
\hline $\begin{array}{l}\text { 412-month } \\
\text { marijuana dependence }\end{array}$ & $5(.7 \%)$ & $0.0(0.0 \%)$ & $0(0.0 \%)$ & $10(1.4 \%)$ & & & & & & & \\
\hline $\begin{array}{l}\text { 66-month } \\
\text { conduct disorder }\end{array}$ & $7(1.0 \%)$ & $0(0.0 \%)$ & $2(.3 \%)$ & $7(1.0 \%)$ & $6(.8 \%)$ & $63(8.6 \%)$ & & & & & \\
\hline $\begin{array}{l}\text { 712-month } \\
\text { major depression }\end{array}$ & $3(.4 \%)$ & $0(0.0 \%)$ & $0(0.0 \%)$ & $3(.4 \%)$ & $1(.1 \%)$ & $5(.7 \%)$ & $26(3.6 \%)$ & & & & \\
\hline $\begin{array}{l}\text { 812-month } \\
\text { dysthymic disorder }\end{array}$ & $0(0.0 \%)$ & $0(0.0 \%)$ & $0(0.0 \%)$ & $1(.1 \%)$ & $1(.1 \%)$ & $2(.3 \%)$ & $1(.1 \%)$ & $6(.8 \%)$ & & & \\
\hline $\begin{array}{l}11 \text { 12-month } \\
\text { oppositional/defiant }\end{array}$ & $4(.5 \%)$ & $0(0.0 \%)$ & $2(.3 \%)$ & $3(.4 \%)$ & $4(.5 \%)$ & $22(2.9 \%)$ & $5(.7 \%)$ & $1(.1 \%)$ & $6(.8 \%)$ & $20(2.7 \%)$ & 58 (7.9\%) \\
\hline
\end{tabular}

children who met criteria for marijuana dependence and six of the nine children who met criteria for nicotine dependence. Thirteen of the 56 children who met criteria for inattention-hyperactive disorder also met criteria for conduct disorder, as did 22 of the 58 children who met criteria for oppositional-defiant disorder. Twenty of the 56 inattentive-hyperactive children also met criteria for oppositional-defiant disorder.

\section{Multivariate analyses}

Separate logistic regression models were used to investigate correlates of meeting criteria for one disorder and for meeting criteria for two or more disorders (Table 4). Because of the potential confound of regressing female caretaker reports of personal psychiatric disorders against female caretaker reports of child disorders, we present both combined female caretaker-child reports and child reports. Of the independent variables regressed on meeting criteria for one mental disorder, only gender, having a female caretaker who met lifetime criteria for major depressive episode, and having a female caretaker who met lifetime criteria for alcohol abuse were statistically significant. Being male increased the odds of meeting criteria for a single mental disorder by $47 \%$. Having a female caretaker who met lifetime criteria for major de-

Table 4. Logistic regression model for 12-month mental disorder and comorbidity among American Indian children (listwise $\mathrm{n}=$ 656)

\begin{tabular}{|c|c|c|c|c|c|c|c|c|}
\hline & \multicolumn{4}{|c|}{ Any single mental disorder } & \multicolumn{4}{|c|}{ Comorbidity } \\
\hline & \multicolumn{2}{|c|}{$\begin{array}{l}\text { Combined caretaker } \\
\text { and child report }\end{array}$} & \multicolumn{2}{|c|}{ Child report } & \multicolumn{2}{|c|}{$\begin{array}{l}\text { Combined caretaker } \\
\text { and child report }\end{array}$} & \multicolumn{2}{|c|}{ Child report } \\
\hline Age & .22 & 1.24 & .41 & $1.50^{*}$ & .39 & $1.47^{*}$ & .49 & 1.64 \\
\hline Gender $($ male $=1)$ & .38 & $1.47^{*}$ & -.30 & .97 & .39 & 1.48 & -.31 & .73 \\
\hline Single parents & .16 & 1.17 & .32 & 1.38 & .45 & 1.57 & -.17 & .84 \\
\hline Female caretaker lifetime GAD & -.27 & 0.76 & -1.32 & .27 & .07 & .94 & -18.77 & 0.00 \\
\hline Female caretaker lifetime MDE & .96 & $2.62^{* *}$ & .68 & $1.98^{*}$ & 1.23 & $3.41^{* *}$ & 1.28 & $3.59^{* *}$ \\
\hline Female caretaker lifetime alcohol abuse & .48 & $1.62^{*}$ & .49 & 1.63 & .30 & 1.35 & .08 & 1.09 \\
\hline Female caretaker lifetime drug abuse & .3 & 1.35 & .32 & 1.37 & .17 & 1.19 & .22 & 1.24 \\
\hline Constant & -4.38 & .01 & -7.28 & 0.00 & 7.79 & 0.00 & -9.27 & 0.00 \\
\hline
\end{tabular}

${ }^{*} p<.05 ;{ }^{* *} p<.01 ;{ }^{* * *} p=.059$ 
pressive episode increased the odds of child mental disorder more than 2.5 times. A female caretaker who met criteria for alcohol abuse increased the odds of offspring mental disorder by $62 \%$.

Gender was nonsignificant in the regression model for child reports, but age was statistically significant. Having a female caretaker who was depressed was significant in the child report model, but female caretaker alcohol abuse was not statistically significant, although the coefficients were essentially the same.

Only two variables were associated with meeting criteria for two or more mental disorders. As one would expect, age was significantly associated with meeting criteria for two more disorders. Having a female caretaker who met lifetime criteria for major depressive disorder increased the probability of child comorbidity almost 3.5 times. Age of child was not statistically significant in the child report model, but female caretaker depression was significant. Given the consistency across reports we believe we can be confident of the association between female caretaker depression and the likelihood of a child meeting diagnostic criteria for one or more disorders.

\section{Discussion}

\section{Comparisons to other diagnostic studies}

When we compare the same reporters (combined caretaker-child reports) the prevalence rates for the various disorders reported here are consistently higher than those among the Cherokee children in the Great Smoky Mountains Study [1]. Rates of substance abuse, behavioral disorders, and depressive disorders were approximately twice those reported in the GSMS. Rates of inattention-hyperactivity disorder were also several times higher. Rates of comorbidity were about three times that reported in the GSMS.

We include these comparisons because GSMS is the only study, of which we are aware, with diagnostic estimates for similarly aged American Indian children. However, it is important to note that differences in prevalence estimates may be attributable to differences in the diagnostic measures used in the two studies. Moreover, some of the variance in estimates may be accounted for by the comparison of three-month versus 12 -month criteria. Regardless, it is noteworthy that the most reliable reporters of behavioral problems, the caretakers $[17,18]$, reported higher prevalence rates in each diagnostic category but substance abuse. In general, our findings indicating higher prevalence rates among the Northern Midwest children than among the GSMS Cherokee children a decade ago should be viewed with appropriate caution. They are intriguing, but far from conclusive.

\section{Maternal psychopathology and child outcomes}

The most striking findings in the multivariate analyses are the associations between female caretaker depression and alcohol use and mental disorder of offspring. These results are congruent with extensive research on the effects of alcohol abuse and depression on the parent-child relationship. Family influences on children's early alcohol and drug use range from biological transmission of vulnerability to ineffective parenting. Although some evidence of direct heritable linkages exists for substance use [22-25], the link is more tenuous than that for related conduct disorder and antisocial behavior [26]. Regardless of heritable predispositions for problem behaviors, family contexts serve to buffer or to incubate their expression [27-29]. Parental substance abuse is strongly associated with ineffective parenting [30-32]. Early-onset substance use is associated with ineffective parenting in the same ways that other problem behaviors are associated with parenting [30,33]. The children in the present study are at particular risk for nonoptimal parenting due to substance abuse. Their adult female caretakers were nearly five times more likely to meet lifetime criteria for alcohol abuse than were females of similar age in the National Comorbidity Survey (66.5\% vs. $14.3 \%$ ) [34].

For decades, evidence has been accumulating indicating that a mother's depressed affect interrupts critical parenting processes. Depressed mothers have been found to be less consistent, more irritable, less spontaneous, and less involved with their children [33-39]. About one in five of the female caretakers in this study met lifetime criteria for major depressive disorder.

\section{Limitations}

The major limitation of this research is the applicability of the DISC-R to children aged 10-12 years. To account for potential problems in reliability we report child reports, caretaker reports, and the combined parent-caretaker reports separately. Reliability research on various versions of the DISC indicate that parent reports are the most reliable and that combined parent-child reports are more reliable than child reports alone $[17,18]$. Another caution in interpreting the results of this study is the sensitivity of DISC-R and UM-CIDI measures for assessing American Indian and Canadian First Nations people. For example, definitions of depression may vary across American Indian cultures, and drinking patterns among American Indian adults may include sporadic binge drinking at irregular intervals that may not be represented adequately by diagnostic criteria [40]. However, this study uses the same measures as recent population studies of American Indian people to provide the best estimates possible [9].

Although we interviewed a broad range of American Indian adults and children on multiple reservations and Canadian reserves that are dispersed geographically 
across two Midwestern states and one Canadian province, these results pertain to a single culture and capture variations within this culture. We believe the findings represent the culture well, but they cannot be generalized to other American Indian cultures. However, if we are to obtain sound psychiatric epidemiological information pertaining to American Indian people, it will be necessary to proceed nation by nation with comparable measures.

A final concern is that this report is limited to $11 \mathrm{di}-$ agnoses for children and only four diagnoses for adults. This limitation was dictated by time, subject burden, and sensitivity of the nations to certain diagnostic questions (e.g., antisocial personality disorders, posttraumatic stress disorder; psychoses).

\section{Clinical implications}

Because it is the only recent diagnostic study of American Indian children in this age range, this research has significant clinical implications. Nearly one-fourth of the children met 12-month criteria for one mental disorder. A very recent report indicates that about one-half of all lifetime mental disorders start by age 14 years [41]. This suggests the need for clinician alertness to potential serious psychological problems. Along with being alert, clinicians should be sensitive to cultural differences in perceptions of psychological distress and service utilization patterns. Often on- or off-reservation physicians are the last choice of treatment for emotional and behavioral troubles in American Indian reservation families [42]. The prevalence of caretaker-child identified behavioral and inattention-hyperactive disorder suggests careful screening and possible inhome behavioral management help for some families. The $5-9 \%$ of the children who already meet criteria for conduct disorder will be those most likely to require long-term services and early intervention to prevent subsequent serious developmental problems. Though a small percentage, the number of children already engaging in alcohol and marijuana abuse is a cause for clinical concern. Drug and alcohol screenings may be indicated among children with other behavioral problems to identify and treat early-onset substance abuse before the consequences impair future life chances and create lasting health problems. Moreover, early nicotine dependence is indicative of life-long tobacco use and the related health risks and costs of treatment of avoidable tobacco-related disease.

Perhaps the most significant findings were the strong effects of female caretaker depression and alcohol abuse on children's mental health. When children present with severe emotional or behavioral problems, it is important to evaluate caretakers who may themselves be in need of support and treatment.

\section{Conclusions}

There are very few psychiatric diagnostic studies of American Indian children, and those that exist typically address only one culture. We need additional culturally sensitive epidemiological studies that progress nation by nation to create a coherent picture of the psychological well-being of American Indian, Alaska Native, and Canadian First Nations children. Although adolescents aged 15 years and older have received attention, Native children are severely understudied and neglected by researchers while at the same time posing significant risk for substance use and mental health problems in later life. We need systematic research to identify risk and protective factors for early mental health problems and identify barriers to services utilization so that we can develop empirically informed, culturally specific prevention programs that address these needs.

Acknowledgments - This research was funded by the National Institute on Drug Abuse (DA13580) and the National Institute of Mental Health (MH67281), Les B. Whitbeck, Principal Investigator.

\section{References}

[1] Costello J, Farmer E, Angold A, et al. Psychiatric disorders among American Indian and White youth in Appalachia: the Great Smoky Mountains Study. Am J Public Health 1997;87:827-32.

[2] Beals J, Manson S, Whitesell N, et al. Prevalence of DSM-IV disorders and attendant help-seeking in 2 American Indian reservation populations. Arch Gen Psychiatry 2005;62:99 -108.

[3] Mitchell C, Beals J, Novins D, et al. Drug use among two American Indian populations: Prevalence of lifetime use and DSM-IV substance use disorders. Drug Alcohol Depend 2003;69:29-41.

[4] Spicer P, Beals J, Croy C, et al. The prevalence of DSM-III$\mathrm{R}$ alcohol dependence in two American Indian populations. Alcohol Clin Exp Res 2003;27:1785-97.

[5] U.S. Department of the Interior, National Park Service. National NAGPRA: Indian reservations in the continental United States map index [cited June 22, 2005]. Online @ http://www.cr.nps.gov/nagpra/DOCUMENT/ResMapIndex.HTM

[6] Beauvais F. Obtaining consent and other ethical issues in the conduct of research in American Indian communities. Drugs \& Society 1999; 14:167- 84.

[7] Norton L, Manson S. Research in American Indian and Alaska Native communities: navigating the cultural universe of values and process. J Consult Clin Psychol 1996;64:856-60.

[8] Trimble J. The sojourner in the American Indian community: methodological issues and concerns. J Soc Issues 1977;33:159 -74.

[9] Beals J, Manson S, Mitchell C, et al. Cultural specificity and comparison in psychiatric epidemiology: walking the tightrope in American Indian Research. Cult Med Psychiatry 2003;27:259-89.

[10] Conger R, Conger K, Elder G, et al. A family process model of economic hardship and adjustment of adolescent boys. Child Dev 1992;63:526-41. 
[11] Kessler R. The National Comorbidity Survey of the United States. Int Rev Psychiatry 1994;6:365-76.

[12] Kessler R. Building on the ECA: the National Comorbidity Survey and the children's ECA. Int J Methods Psychiatr Res 1994;4:81-94.

[13] World Health Organization. Composite International Diagnostic Interview (CIDI), Version 1.0. Geneva: World Health Organization, 1990.

[14] Schwab-Stone M, Fallon T, Briggs M, et al. Reliability of diagnostic reporting for children aged 6-11 years: a testretest study of the Diagnostic Interview Schedule for Children-Revised. Am J Psychiatry 1994;151:1048 -54.

[15] Shaffer D, Schwab-Stone M, Fisher P, et al. The Diagnostic Interview for Children-Revised Version (D(SC-R): I. Preparation, field testing, interrater reliability and acceptability. J Acad Child Adolesc Psychiatry 1993;32:643-50.

[16] Shaffer D, Schwab-Stone M, Fisher P, et al. A Revised Version of the Diagnostic Interview Schedule for Children (DISC-R): Results of a Field Trial and Proposals for a New Instrument (DISC-2). Rockville, MD: Epidemiology and Psychopathology Research Branch, Division of Clinical Research, National Institute on Mental Health, 1988.

[17] Schwab-Stone M, Shaffer D, Dulcan M, et al. Criterion validity of the NIMH Diagnostic Interview Schedule for Children verion 2.3 (DISC- 2.3). J Acad Child Adolesc Psychiatry 1996;35:878-88.

[18] Shaffer D, Fisher P, Dulcan M, et al. The NIMH Diagnostic Interview Schedule for Children (DISC-2): description, acceptability, prevalences and performance in the MECA study. J Acad Child Adolesc Psychiatry 1996;35:865-77.

[19] Bird H, Gould M, Staghezza B. Aggregating data from multiple informants in child psychiatry epidemiological research. J Acad Child Adolesc Psychiatry 1992;31:78-85.

[20] Jensen P, Rubio-Stipec M, Canino G, et al. Parent and child contributions to diagnosis of mental disorder: are both informants always necessary? J Acad Child Adolesc Psychiatry 1999;38:1569 -79.

[21] Hart E, Lahey B, Loeber R, et al. Criterion validity of informants in the diagnosis of disruptive behavior disorders in children: a preliminary study. J Consult Clin Psychol 1994;62:410-4.

[22] Cadoret R, Troughton E, O'Gorman T, et al. Adoption study demonstrating two genetic pathways to drug use. Arch Gen Psychiatry 1995;42:1131- 6.

[23] Cadoret R, Yates W, Troughton E, et al. An adoption study of drug abuse/dependence in females. Compr Psychiatry 1996;37:89 -94.

[24] Merikanguas K, Rousavillle B, Prusoff B. Familial factors in vulnerability to substance abuse. In: Glantz M, Pickens R, eds. Vulnerability to Drug Use. Washington, DC: American Psychological Association, 1992:75-97.

[25] Gordis E, Tabakoff B, Goldman D, et al. Finding the gene(s) for alcoholism. JAMA 1990;263:2094 -5.

[26] Moffitt TE. Adolescent-limited and life-course-persistent offending: a complimentary pair of developmental theories. In: Thornberry T, ed. Developmental Theories of Crime and Delinquency. New Brunswick, NJ: Transaction, 1997:11-54.
[27] Patterson GR. Coercive Family Process. Eugene, OR: Castilia, 1982.

[28] Rutter M, Quinton D, Hill J. Adult outcomes of institution-reared children: males and females compared. In: Robins L, Rutter M, eds. Straight and Deviant Pathways from Childhood to Adulthood. Cambridge, England: Cambridge University Press, 1990:135-57.

[29] Conger R. The social context of substance abuse: a developmental perspective. In: Robinson E, Sloboda Z, Boyd E, et al, eds. Rural Substance Abuse: State of Knowledge and Issues (NIDA Research Monograph No. 168; NIH Publication No.97-4177. Washington, DC: National Institute on Drug Abuse, 1997:6 -36.

[30] Conger R, Reuter M, Conger K. The family context of adolescent vulnerability and resilience to alcohol use and abuse. Soc St Children 1994;6:55- 86.

[31] Loeber R, Farrington D, Stouthamer-Loeber M, et al. Antisocial Behavior and Mental Health Problems. Mahwah, NJ: Lawrence Erlbaum, 1998.

[32] Dishion T, Loeber R. Adolescent marijuana and alcohol use: the role of parents and peers revisited. Am J Drug Alcohol Abuse 1985;11: 11-25.

[33] Whitbeck L, Hoyt D, Chen X, et al. Prevalence and comorbidity of American Indian adults in the northern Midwest. In press.

[34] Beardslee W, Bemporad J, Keller M, et al. Children of parents with major affective disorder: a review. Am J Psychiatry 1983;140:825- 32.

[35] Billlings AG, Moos RH. Comparisons of children of depressed and nondepressed parents: a social-environmental perspective. J Abnorm Child Psychol 1983;11:463- 86.

[36] Ovaschel H. Maternal depression and child dysfunction. In: Lahey B, Kazdin A, eds. Advances in Social Psychology. New York, NY: Plenum Press, 1983:169 -97.

[37] Patterson G. Dishion T. Multilevel process models: traits, interactions, and relationships. In: Hinde $R$, StevensonHinde J, eds. Relationships within Families. Oxford, UK: Clarendon Press, 1988:383- 410.

[38] Weissman M, Paykel E, Klerman G. The depressed woman as mother. Soc Psychiatry 1972;7:98 -108.

[39] Whitbeck L, Hoyt D, Simons R, et al. Intergenerational continuity of parental rejection and depressed affect. J Pers Soc Psychol 1992;63: 1036-45.

[40] Manson S, Shore J, Boom J. The depressive experience in American Indian communities: a challenge for psychiatric theory and diagnoses. In: Kleinman A, Good B, eds. Culture and Depression: Studies in the Anthropology and Cross-Cultural Psychiatry of Affect and Disorder. Berkeley, CA: University of California Press, 1985:331- 68.

[41] Kessler R, Bergland P, Demler O, et al. Lifetime prevalence and age of onset distributions of DSM-IV Disorders in the National Comorbidity Survey Replication. Arch Gen Psychiatry 2005;62:593- 602.

[42] Walls M, Johnson K, Whitbeck L, et al. Mental health and substance abuse services preferences and utilization patterns among American Indian people in the northern Midwest. In press. 